NASA Technical Memorandum 107490

AIAA-97-3142

\title{
Numerical Assessment of Four-Port Through-Flow Wave Rotor Cycles With Passage Height Variation
}

D.E. Paxson and Jules W. Lindau

Lewis Research Center

Cleveland, Ohio

Prepared for the

33rd Joint Propulsion Conference and Exhibit cosponsored by AIAA, ASME, SAE, and ASEE

Seattle, Washington, July 6-9, 1997

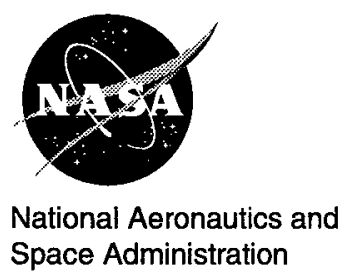




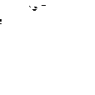




\title{
NUMERICAL ASSESSMENT OF FOUR-PORT THROUGH-FLOW WAVE ROTOR CYCLES WITH PASSAGE HEIGHT VARIATION
}

\author{
D. E. Paxson \\ NASA Lewis Research Center \\ Cleveland, Ohio, USA \\ Jules W. Lindau* \\ NASA Lewis Research Center \\ Cleveland, Ohio, USA
}

\begin{abstract}
The potential for improved performance of wave rotor cycles through the use of passage height variation is examined. A Quasi-one-dimensional CFD code with experimentally validated loss models is used to determine the flowfield in the wave rotor passages. Results indicate that a carefully chosen passage height profile can produce substantial performance gains. Numerical performance data are presented for a specific profile, in a four-port, through-flow cycle design which yielded a computed $4.6 \%$ increase in design point pressure ratio over a comparably sized rotor with constant passage height. In a small gas turbine topping cycle application, this increased pressure ratio would reduce specific fuel consumption to $22 \%$ below the untopped engine; a significant improvement over the already impressive $18 \%$ reductions predicted for the constant passage height rotor. The simulation code is briefly described. The method used to obtain rotor passage height profiles with enhanced performance is presented. Design and off-design results are shown using two different computational techniques. The paper concludes with some recommendations for further work.
\end{abstract}

\section{Introduction}

Pressure-gain wave rotors represent a promising technology for use as high pressure, high temperature topping cycles in gas turbine engines. ${ }^{1-3}$ These devices utilize unsteady gasdynamic waves, rather than the airfoils of their conventional turbomachinery counterparts, to transfer energy to and from the working fluid. Besides significantly improving the performance of gas turbine engines which they top, the potential advantages of wave rotors include rotor metal temperatures substantially below the combustor discharge temperature, rotational speeds which are approximately one third those of conventional turbomachinery for the same application, a wide operating range, ${ }^{4}$ and relatively simple rotor geometry. Recent research efforts have focused largely on fourport, through-flow cycles with axially aligned passages

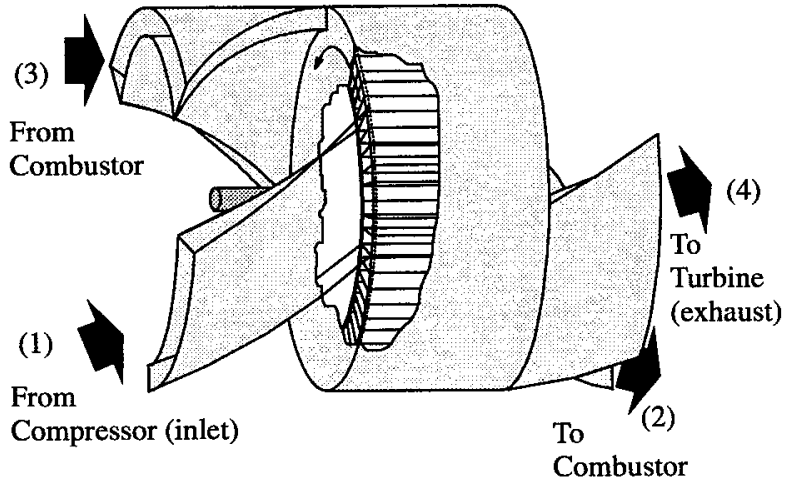

Figure 1 Example four-port wave rotor.

of uniform cross section. This design, shown schematically in Fig. 1, is attractive in that, aside from the difficulty of partial to full annular transition ducts, it can be readily integrated into existing gas turbine engines as another spool. ${ }^{5}$

The term 'through-flow' refers to the general tendency for all of the flow entering the wave rotor to completely traverse the passage before exiting. In other words, the flow comes in one end and out the other. In contrast, there are reverse-flow cycles which draw in gas through one port and discharge it through another at the same end of the rotor. In these cycies, with reference to Fig.1, air would enter the rotor through port 1 and be sent to the combustor through port 3 . Thus, in a reverse-flow cycle each gas stream entering the passages tends to remain close to one end of the rotor. ${ }^{1}$

Although the predicted performance benefits of wave rotors are impressive, there is always room for improvement. With reference to Fig. 1, the higher the overall stagnation pressure ratio of the device, $\mathrm{p}_{04} / \mathrm{p}_{01}$, the greater the performance benefit to the gas turbine that it tops. ${ }^{1}$ These performance benefits include reduced specific fuel consumption (SFC) and increased specific power. Indeed, for small turboshaft engines,

\footnotetext{
${ }^{*}$ National Research Council—NASA Research Associate at Lewis Research Center
} 
with today's turbine inlet temperatures, there is nearly a one-to-one correspondence between SFC reduction and wave rotor pressure ratio. That is, a $1 \%$ increase in $\mathrm{p}_{04} / \mathrm{p}_{01}$ yields a $1 \%$ decrease in SFC. Thus, for many envisioned wave rotor topped gas turbine engines there is strong motivation for even small wave rotor performance enhancement.

Significant analytical and computational efforts have been directed toward optimizing four-port, pressuregain wave rotors in order to maximize their performance; however, until recently, these efforts have been constrained to passages which have uniform cross section., 6 There seem to be several historical reasons for this restriction. The first is that there is a greater knowledge base of the one-dimensional flowfields that constant area cross sections imply. Secondly, there is little to suggest that cross sectional area variation should be beneficial. ${ }^{7}$ Third, and this is clearly related to the second reason, there is nothing to suggest a particular manner in which the passage height ought to be varied in order to achieve greater performance. Even if one could incorporate area variation into the analyses, what area profile should be chosen? During earlier research periods, when computers were not yet available and wave rotor cycles were laboriously calculated by hand, the answer to this question was simply out of the researchers grasp. Calculation of a single cycle was literally weeks worth of work and, although incorporating area variation into analysis techniques such as the Method of Characteristics was reasonably straightforward, any additional degree of freedom meant just that many more cycles to calculate. The task would have been daunting. Today however, the calculation of a design point wave rotor cycle takes seconds (or less) on a modern computer and it does not seem so overwhelming to attempt at least an exploratory foray into the potential benefits of area variation. Although there is little information suggesting a particular optimal profile, it is relatively easy to try many variants and thus make some headway.

This paper will present the preliminary results from just such an activity and, as will be seen, the results are quite promising. It will be shown, to the degree that the numerical methods are accurate, that pressure ratios up to $4.6 \%$ greater than those of the four-port pressure exchanger with constant cross section are possible. It is emphasized that this is indeed a preliminary result because this investigation represents only a 'first cut' at the potential benefits of area variation. The possible area profiles were fairly restricted and, although substantial gains were obtained, no general methodology or even guideline was found. In other words, there is still quite possibly a good deal more

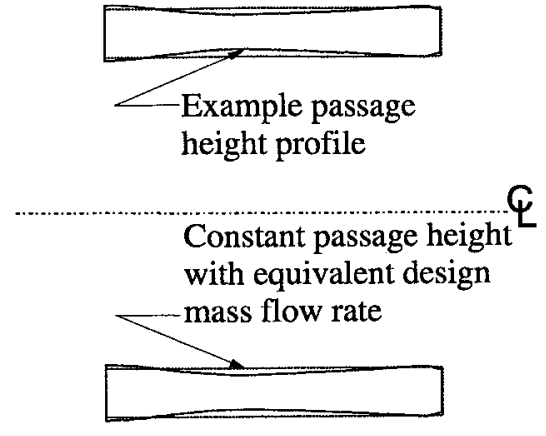

Figure 2 Example of passage height variation.

benefit to be gained.

Under the assumption of quasi-one-dimensional (heretofore referred to as Q1D) flow of an ideal gas, the governing equations will be presented. The numerical integration method will then be briefly presented; however, this presentation will rely heavily on past publications of an experimentally validated numerical wave rotor simulation code. ${ }^{4,8,9}$ The approach used to find an area profile which yielded improved performance will then be described. Wave diagrams as well as on and off-design performance data will then be presented and compared with that from a constant cross section passage for a four-port, through-flow cycle designed to top a small helicopter engine with a mass flow rate of approximately $4.8 \mathrm{lbm} / \mathrm{s}$, and an upstream compressor pressure ratio of 7.8. The paper will conclude with a discussion of the results, and recommendations for further work.

\section{Governing Equations}

The variation in cross sectional area is assumed to be gradual for this study. The passage cross section is assumed trapezoidal with constant mean width. Thus, as illustrated in Fig. 2, the area variation comes from changes in the passage height. Under these assumptions and that of a perfect gas, the governing equations for a wave rotor passage may be written in non-dimensional form as follows

$$
\frac{\partial \overline{\mathrm{w}}}{\partial \tau}+\frac{\partial \overline{\mathrm{F}}(\overline{\mathrm{w}})}{\partial \mathrm{x}^{\prime}}=\overline{\mathrm{S}}(\overline{\mathrm{w}})
$$

where

$$
\bar{w}=\left[\begin{array}{c}
\rho^{\prime} h^{\prime} \\
\rho^{\prime} u^{\prime} h^{\prime} \\
\frac{p^{\prime} h^{\prime}}{\gamma(\gamma-1)}+\rho^{\prime} h^{\prime} u^{\prime 2}
\end{array}\right]
$$




$$
\bar{F}=\left[\begin{array}{c}
\rho^{\prime} u^{\prime} h^{\prime} \\
\frac{p^{\prime} h^{\prime}}{\gamma}+\rho^{\prime} h^{\prime} u^{\prime 2} \\
\frac{p^{\prime} h^{\prime} u^{\prime}}{(\gamma-1)}+\frac{\rho^{\prime} h^{\prime} u^{\prime 3}}{2}
\end{array}\right]
$$

The distance, $\mathrm{x}^{\prime}$ has been normalized by the passage length, $L$. The time, $\tau$ has been normalized by the characteristic wave transit time, $\mathrm{L} / \mathrm{a}^{*}$, where $\mathrm{a}^{*}$ is the reference speed of sound. The pressure, $p^{\prime}$ and density, $\rho^{\prime}$ have been normalized by their respective reference values and the axial velocity, $u^{\prime}$ has been normalized by $a^{*}$. The passage height, $h^{\prime}$ has been normalized by the reference value $h^{*}$. The ratio of specific heats is denoted by $\gamma$.

In the constant cross sectional area formulation, the source vector, $\overline{\mathbf{S}}(\overline{\mathrm{w}})$ accounts for viscous, heat transfer, and leakage effects. Details on the exact form of the components may be found in Refs. 8 and 9. In the Q1D formulation, these effects are modeled in same manner; however, there is an additional component to the momentum source term giving it the following form:

$$
S_{2}=S_{2}^{\text {friction }}+p^{\prime} \frac{d h^{\prime}}{d x^{\prime}}
$$

\section{Numerical Integration}

The scheme used to numerically integrate Eq. (1) with constant cross section has been detailed in Refs. 4 and 9. It is a Lax-Wendroff based scheme which utilizes Roe's approximate Riemann solver to obtain flux estimates at the numerical cell faces. ${ }^{10,11}$ Roe's method utilizes the primitive variables $p^{\prime}, \rho^{\prime}$, and $u^{\prime}$ to obtain an approximate solution to a one-dimensional Riemann problem with an arbitrary left and right state. Area variation (quasi-one-dimensional) can easily be incorporated into this method by replacing $p$ and $\rho$ with the products $\mathrm{p}^{\prime} \mathrm{h}$ ' and $\rho ' \mathrm{~h}$ ', respectively. The additional term in the source vector, Eq. (4) is dealt with in the same manner as other source terms, with the spatial height derivative being estimated using central differencing.

\section{Test Cases}

The numerical integration scheme was tested using three flow scenarios. The first is an inviscid, steadystate, converging-diverging nozzle containing a normal shock in the diverging section. While this is not a scenario that will be found in wave rotor applications, it is convenient because there is a theoretically exact

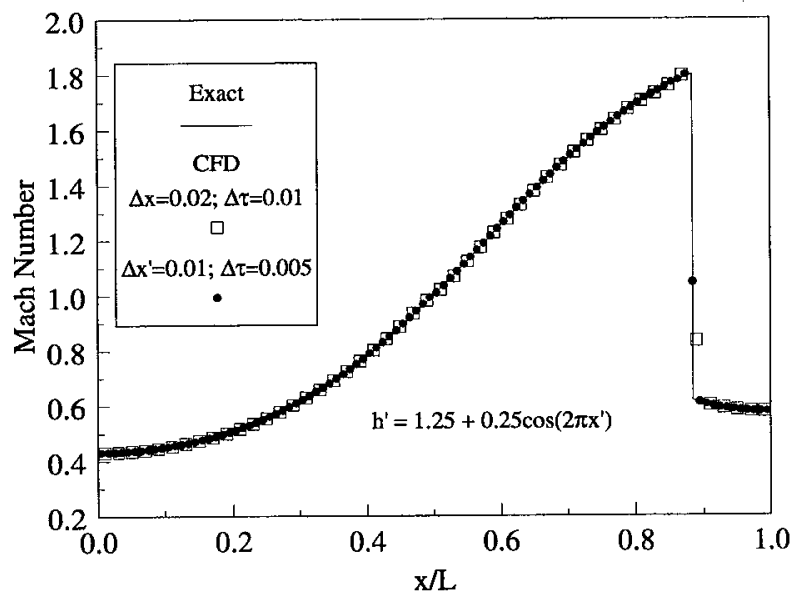

Figure 3 Computed and exact mach number distributions for a steady-state converging-diverging nozzle.

solution with which to compare results. Figure 3 compares Mach numbers for the computed and exact flowfield solution with a passage height profile described by $h^{\prime}=1.25+0.25 \cos \left(2 \pi x^{\prime}\right)$. The value of $\gamma$ is 1.4. Numerical solutions using both 50 and 100 numerical cells are shown and in both cases agreement with the exact solution is excellent.

The second test flow scenario is more relevant because it is unsteady. Unfortunately, there is no exact solution to this problem. It was possible however, to compare the solution from the present computational scheme with two other types of numerical solutions. The first is the Method of Characteristics. ${ }^{7,12}$ The second is a fully two-dimensional, unsteady CFD code. ${ }^{13}$ The scenario is that of a passage with a cross section described by $h^{\prime}=1.0+0.8 x^{\prime}$. The inviscid fluid in the passage is initially at rest with a non-dimensional pressure and density equal to unity. At $\tau=0$ the right end of the passage is suddenly opened to a reservoir at pressure $\mathrm{p}^{\prime}=0.471$. This initiates a strong expansion wave which travels leftward, reflects from the wall, and returns to the right end. The velocity at the right end of the passage is eventually brought to zero by the reflected expansion and at this point the right end of the passage is closed. Figure 4 shows a comparison between the results from the present Q1D approach, the Method of Characteristics scheme, and the two-dimensional code. Non-dimensional time traces of pressure along the left wall and velocity along the right end of the passage, as computed by the three methods, are shown. The twodimensional results were taken from the mid-height numerical cells. For reference, contours of pressure in the $\mathrm{x}-\mathrm{t}$ space, computed using the present Q1D scheme are shown in the center of the figure. The value of $\gamma$ for 

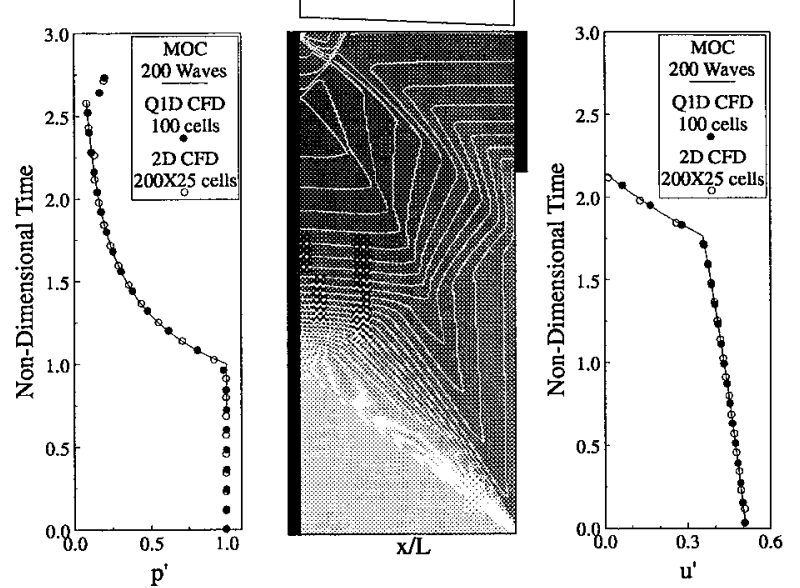

Figure 4 Traces of pressure at the closed end and velocity at the open end of a variable area passage with a reflected expansion wave initiated at the right end, computed using the Method of Characteristics, a 2D CFD code, and the present Q1D CFD scheme.

this test was 1.4. It is evident that all three computational methods agree very well.

The third test scenario investigated was a simple resonance test. A pipe of uniform cross section, closed at one end, and filled with an inviscid fluid has a fundamental acoustic resonance frequency that is one half that of a cone of the same length and with the same maximum radius. ${ }^{14}$ Furthermore, the overtones for the constant cross section pipe are odd multiples of the fundamental mode, while they are integer multiples for the cone. An effective conical shape can be simulated in Eq. (1) by using a parabolic height profile. These acoustic tests were conducted with the present numerical scheme using a sinusoidal excitation pressure perturbation at the open ends. The initial pressure in the pipe and cone was unity. The peak-to-peak pressure perturbation was 0.002 . The results are not shown here; however, it was found that the present numerical scheme successfully demonstrated resonance for both the straight pipe and cone, at the appropriate frequencies, for both the fundamental and second modes. Higher modes were not examined. It was not possible to numerically describe a perfect vertex for the cone (i.e. having no area). The area of the numerical cell at the tip of the cone was $0.5 \%$ of the maximum area. The numerical simulations were performed with a spatial resolution of $\Delta x^{\prime}=0.01$ and a time step of $\Delta \tau=.005$.

The test cases described above do not imply formal validation of the computational method; however, the results are at least encouraging.
Table 1 Variable passage height design constraints.

\begin{tabular}{ll}
\hline \hline Mid-Height Passage Width & $0.34 \mathrm{in}$. \\
Reference Passage Height, $\mathrm{h}^{*}$ & $0.86 \mathrm{in}$. \\
Rotor Length & $6.00 \mathrm{in}$. \\
Mean Rotor Radius & $3.21 \mathrm{in.}$ \\
Rotor Rotational Speed & $16,800 \mathrm{rpm}$ \\
Inlet Mass Flow Rate & $4.78 \mathrm{bm} / \mathrm{s}$ \\
$\mathrm{T}_{04} / \mathrm{T}_{01}$ & 2.21 \\
Inlet Stagnation Pressure & $114.2 \mathrm{psia}$ \\
Inlet Stagnation Temperature & $1081.7 \mathrm{R}$ \\
Mean Ratio of Specific Heats & 1.353 \\
Constant Passage Height $\mathrm{p}_{04} / \mathrm{p}_{01}$ & 1.203 \\
\hline
\end{tabular}

\section{Height Profile Selection}

As mentioned in the introduction, there do not appear to be any clear guidelines in the literature for choosing a passage height profile which yields enhanced performance. The strategy of this investigation was to utilize the most geometrically simple profile possible. The motivation for such an approach was simply that less complex profiles have less parametric variants to consider.

For all of the profiles chosen, the cycle design method described in Ref. 3 was used to obtain circumferential port locations, port pressures and temperatures, and reference passage heights, subject to the fixed design constraints shown in Table 1 . Briefly this method utilizes the numerical simulation described above to perform a multi-level iteration, the convergence of which produces a cycle with port placement to properly initiate or reflect waves (i.e., only at port openings and closings), and port boundary conditions to insure that the same amount of mass leaves the wave rotor as enters in a single cycle. Since it utilizes the CFD code described above, the design method accounts for the same losses, namely those due to viscosity and gradual passage opening. Heat transfer, leakage, and incidence losses are not incorporated in the design method; however, they are included in general numerical simulations. Bleed flows for cooling of downstream turbine components and ducts can also be accounted for in the design code; however, bleed was not used in this study.

The fixed design constraints shown in Table 1 were taken from an optimized constant area wave rotor designed for topping a small helicopter engine. ${ }^{1,5}$ As a result, the optimal performance enhancement profile to be shown is specific to this small engine application. The reference height listed in Table 1 is also the constant passage height design value. The performance figure of merit used for the investigation was the overall stagnation pressure ratio, $\mathrm{p}_{04} / \mathrm{p}_{01}$. The free parameters 
in the design method were the height profile and the expansion ratio, $\varepsilon$ which is the ratio of assumed constant static pressure in port 4 of Fig. 1 to the assumed uniform pressure in the passage just before it opens to port 4. For each height profile tested the expansion ratio yielding maximum performance was found by trial and error. It was always within $10 \%$ of the optimal, constant height value of 0.40 .

\section{Profiles Described by a Single Slope}

The first height profiles examined were described by straight converging or diverging lines of various slopes. It was found that passages which diverged in the direction of flow showed decreased performance compared to the constant height passage. Passages with converging profiles showed slight improvements with overall pressure ratio reaching a maximum of approximately $1.8 \%$ above the constant height value when the slope of the passage height, $\mathrm{dh}^{\prime} / \mathrm{dx}^{\prime}$ was -0.37 .

\section{Profiles Described by Two Slopes and a Vertex}

Height profiles described by two slopes and a vertex were examined next. It was found that those profiles which converged then diverged in the flow direction showed significant performance improvement. In particular, a profile with non-dimensional converging slope, diverging slope, and axial location of the vertex of $-1.97,0.37$, and 0.39 respectively raised the overall pressure ratio to $3.4 \%$ above the constant height value.

\section{Converging-Diverging-Converging Profiles}

The converging-diverging profiles yielded even higher performance when a second, much shorter converging section was added after the diverging section. The profile of this type yielding the highest performance is shown in Fig. 2. The profile has been smoothed using a curve-fit procedure which removes the discontinuous slopes at the vertices and assures that the slopes are zero at the ends of the passage. This was the last profile examined; however, it is noted that the examination was not exhaustive. Clearly, each new degree of freedom in the height profile description greatly increases the scope of the parametric analysis and a complete parametric study of the converging-diverging-converging profiles was beyond the scope of this paper. For reference, Fig. 2 also shows the constant height profile giving the same mass flow rate under the constraints listed in Table 1.

\section{Design Point Performance}

The design point overall pressure ratio obtained using the optimal passage height configuration shown in Fig. 2 was 1.255 . This value was obtained with heat transfer effects included and an assumed endwall leakage gap of 0.005 in. which is the same as that used in the constant passage height simulation with which the Table 1
Table 2 Design point port conditions for a wave rotor with and without passage height variation

\begin{tabular}{ccccc}
\hline \hline $\begin{array}{c}\text { Port \# } \\
\text { Variable } \mathrm{h}\end{array}$ & & & & \\
(Constant h) & $\mathrm{p}_{0}$ & $\mathrm{~T}_{0}$ & Mach \# & Mass Flow Rate \\
1 & 1.00 & 1.00 & 0.43 & 1.00 \\
& $(1.00)$ & $(1.00)$ & $(0.51)$ & $(1.00)$ \\
2 & 3.56 & 2.06 & 0.36 & 1.50 \\
& $(3.26)$ & $(2.04)$ & $(0.38)$ & $(1.54)$ \\
3 & 3.32 & 2.87 & 0.31 & 1.50 \\
& $(2.97)$ & $(2.82)$ & $(0.40)$ & $(1.54)$ \\
4 & 1.26 & 2.21 & 0.60 & 1.00 \\
& $(1.20)$ & $(2.21)$ & $(.60)$ & $(1.00)$ \\
\hline \hline
\end{tabular}

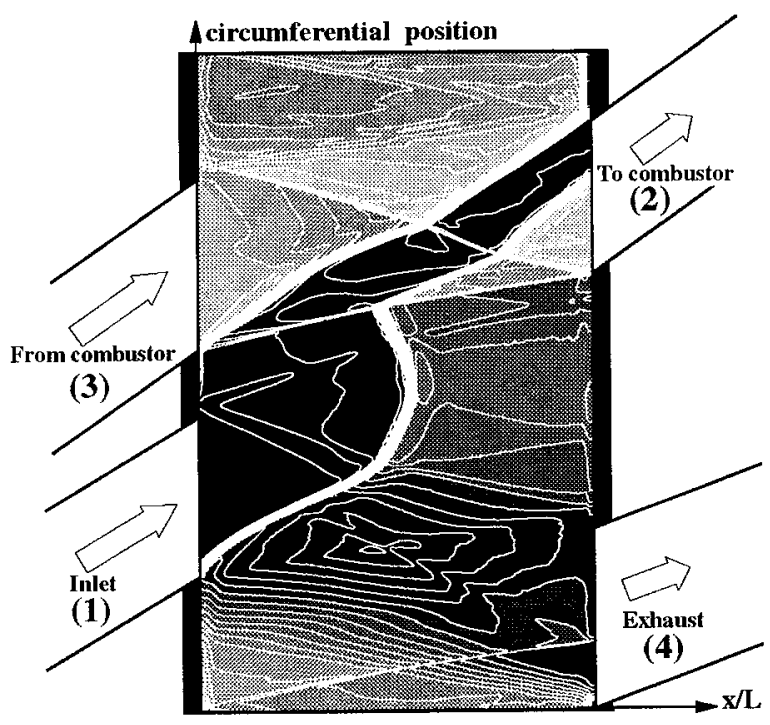

Figure 5 Computed design point wave diagram with optimal passage height profile, shown using contours of temperature.

baseline pressure ratio of 1.203 was obtained. The computed design point wave diagram is shown in Fig. 5 using contours of temperature. The areas between the contour lines have been gray-shaded such that dark grays represent relatively cool regions and light grays represent hot regions. The use of temperature contours allows waves patterns and a limited number of particle paths to be seen simultaneously. Figure 5 is unremarkable in that there is nothing obvious which distinguishes the wave pattern from that of a four-port cycle with constant passage height. For reference, Fig. 5 was computed using 100 numerical cells with a corresponding numerical time step of $\Delta \tau=.003$.

The design point stagnation conditions and Mach numbers for each of the four ports shown in Fig. 1 (and Fig. 5) are listed in Table 2. For ports in which there is 


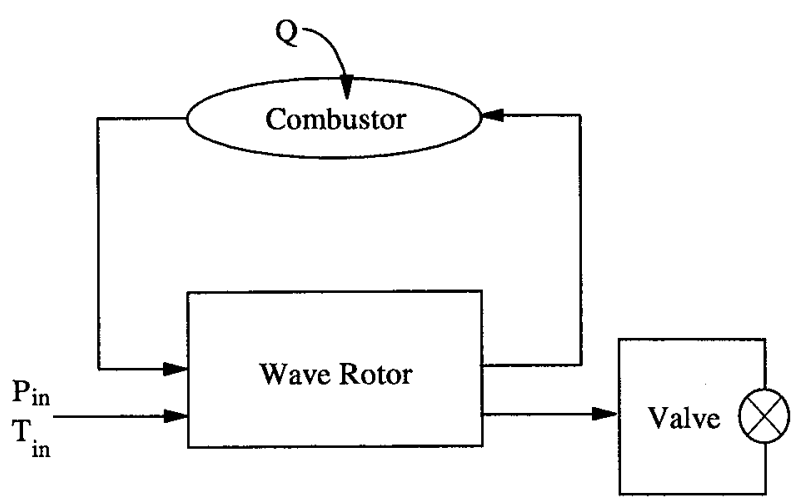

Figure 6 Schematic of the numerical test bed.

flow into the wave rotor, the stagnation conditions are either specified in the case of port 1 , or supplied by component sub-models in the case of port $3 .^{8}$ For outflow ports 2 and 4, the stagnation conditions are calculated using a constant area mixing calculation to account for losses due to non-uniformities in the port flowfield (see for example the velocity distribution in Fig. 4). The stagnation conditions and mass flow rates in Table 2 have been normalized by those from the inlet. For reference, the port states for the constant passage height rotor design are also listed in Table 2. Here, the differences between constant and variable passage height are clearer. The compression achieved by the variable height cycle, $\mathrm{p}_{02} / \mathrm{p}_{01}$ is $9.2 \%$ higher than the constant height cycle. Furthermore, the stagnation pressure drop across the combustor required to balance the cycle drops from $8.9 \%$ of the port 2 stagnation pressure, for the constant height rotor to $6.7 \%$ for the variable height rotor. These results are consistent with the improved overall pressure ratio of the variable height cycle, suggesting a higher compression efficiency and a better match between compression and expansion processes.

\section{Off-Design Performance}

The off-design performance will be examined in two ways. The first will be a presentation of a performance map which encompasses the entire potential operating regime of the wave rotor in an engine topping environment. The second will be through detailed views of wave diagrams at several off-design operating points.

\section{Performance Map}

The performance map was generated using a numerical 'test bed' shown schematically in Fig. 6. The wave rotor component was simulated using the scheme described earlier. The other components shown in the figure were simulated using simple, lumped-capacitance models. ${ }^{4}$ Discrete spatial and temporal steps of $\Delta x=.02$

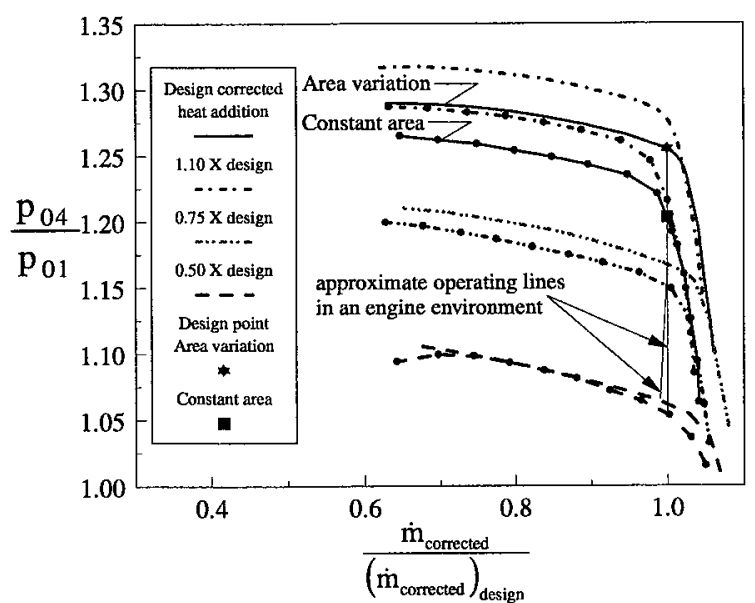

Figure 7 Four-port wave rotor performance map with and without area variation.

and $\Delta t=.005$, respectively were used. The wave rotor cycle described in this paper was designed to operate in a so-called freewheeling mode. This means that there is no drive motor to turn the rotor. The small amount of torque required is generated by changes in angular momentum as fluid in the inlet ducts is turned from the duct angles to follow the walls of the rotor. Windage and bearing friction are neglected. Inefficiencies associated with the flow turning process are modeled as incidence losses. For a given operating point, the rotor speed changes until the net torque generated by the inlet ports is zero. With this type of design, and the perfect gas assumption, the steady-state performance of a wave rotor may be displayed on a single map consisting of families of curves with fixed corrected heat addition rates (fuel flow rates) plotted with corrected mass flow on the ordinate and overall pressure ratio on the abscissa. Such a map is shown in Fig. 7. The map shows performance for both the variable and constant height wave rotor designs. The constant height results are shown with symbols and lines. The variable height results are shown with only lines. For reference, the corrected mass flow rate is defined as

$$
\dot{\mathrm{m}}_{\mathrm{c}}=\frac{\dot{\mathrm{m}}}{\mathrm{p}_{01} \mathrm{~A}_{1}} \sqrt{\frac{R \mathrm{~T}_{01}}{\mathrm{~g}_{\mathrm{c}}}}
$$

where $\dot{m}$ is the mass flow rate, $p_{01}$ and $T_{01}$ are the inlet stagnation pressure and temperature respectively, $A_{1}$ is the inlet cross sectional area, $R$ is the gas constant, and $\mathrm{g}_{\mathrm{c}}$ is the Newton constant. The corrected heat addition rate is defined as

$$
\dot{\mathrm{Q}}_{\mathrm{c}}=\frac{\dot{\mathrm{Q}}}{\mathrm{p}_{01} \mathrm{~A}_{1} \sqrt{R \mathrm{~T}_{01} \mathrm{~g}_{\mathrm{c}}}}
$$


where $\dot{Q}$ is the heat addition rate. The corrected heat addition and corrected mass flow are shown in Fig. 7 as fractions of the design point value in order to facilitate a more direct comparison between the variable and constant passage height cycles. Also shown in Fig. 7 is an approximate operating line, in an engine environment. The line represents operation from a near idle condition to $100 \%$ of power. It can be seen in this figure that the variable height design out performs the constant height design over the normal operating regime in a topping cycle environment. Furthermore, it is clear that, like the constant height design, the complete range of operation for the variable height design is quite large. This is an encouraging result, and parenthetically, somewhat counterintuitive given that many turbomachinery performance increases come at the expense of reduced operating range.

\section{Off-Design Wave Diagrams}

The off-design wave diagrams were made using a steady-state, quasi-three-dimensional CFD code (heretofore referred to as Q3D). ${ }^{15,16}$ Details of the Q3D formulation may be found in Appendix 1. Briefly, the term quasi-three-dimensional refers to a curvilinear geometry bound by surfaces of revolution composed of the inner and outer surfaces of the wave rotor. The flow field is restricted to a surface of revolution midway between the two bounding surfaces. Variation normal to this mean surface is neglected, and the modeled flow becomes two-dimensional in the circumferential, and meridional directions. Effects of radius and flowpath height variation are thus captured; however no radius variation was considered in this investigation.

Unlike the Q1D code the Q3D code has the capability of simulating the interactions between flowfields in the wave rotor ducts and those on board the rotor itself. These interactions are present in any wave rotor and thus, the results presented herein are quite general. It has been suggested that these interaction may be quite important for accurate flowfield predictions, particularly in off design scenarios where inflow to the rotor may occur in ducts which are designed for outflow, and where pressure gradients across the ducts may be large, thus invalidating the constant pressure boundary assumption of the one-dimensional, and Q1D unsteady codes. ${ }^{15}$ This section of the paper will therefore serve the dual purposes of illustrating some aspects of off-design wave rotor operation, and assessing the importance of duct/rotor flowfield interactions. Results from the Q3D code will be compared to the previously described Q1D code. Boundary conditions for ports 1,3 , and 4 in the Q3D code were provided by running the Q1D code in the

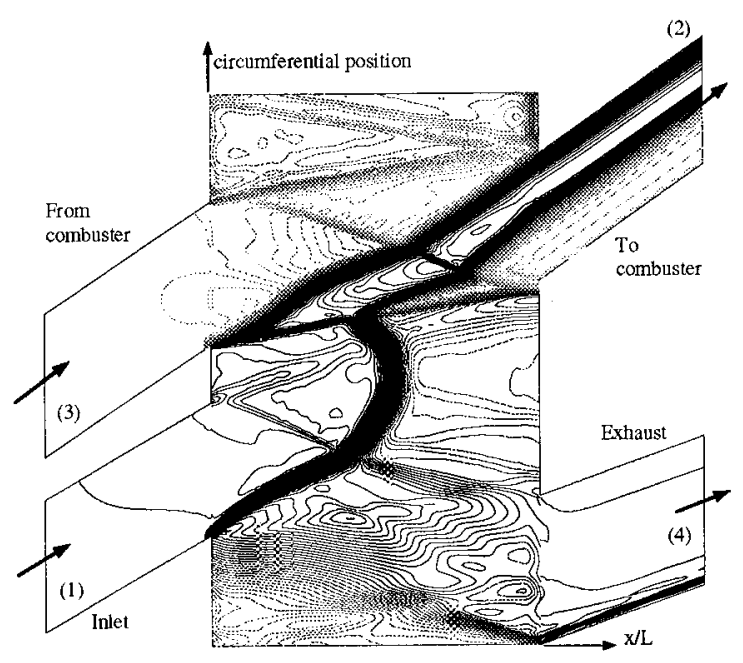

Figure 8 Q3D simulation of design point wave diagram, with optimal passage height profile, neglecting gradual opening time, heat transfer, and leakage effects; shown using contours of temperature.

simulation mode described by Fig. 6. The port 2 boundary conditions were determined by matching the mass flow through ports 2 and 3. The Q3D code uses sub-models similar to those in the quasi-onedimensional code to capture the effects of viscous and incidence losses. No sub-models have been implemented to assess leakage, heat transfer, or gradual passage opening effects. As a result, the Q1D code was, for this portion of the investigation, run with these effects disabled. Rotor speed changes associated with the free-wheeling mode of operation also have not been implemented in the Q3D code. Thus, it is run at a specified, fixed speed. For reference, a five zone grid was used for all Q3D calculations with 101 (axial) by 201 (circumferential) cells in the rotor zone, 26 by 49 in port 1,26 by 47 in port 2,26 by 53 in port 3 , and 26 by 55 in port 4.

\section{Design Point}

The port timing for the optimal passage height profile was designed with the effects of gradual opening time accounted for. Since the Q3D code does not have these effects modeled, and since finite opening time has a substantial effect on the speed of waves in a cycle, it stands to reason that the 'design point' simulation of this cycle would in fact be off-design. In a wave diagram, this would be evidenced by waves that do not coincide with port openings and closings, and by spurious waves in the $\mathrm{x}-\mathrm{t}$ space. That this is the case is evident in Fig. 8. This wave diagram, again made with contours of temperature, represents the wave rotor operating at approximately the same overall temperature 

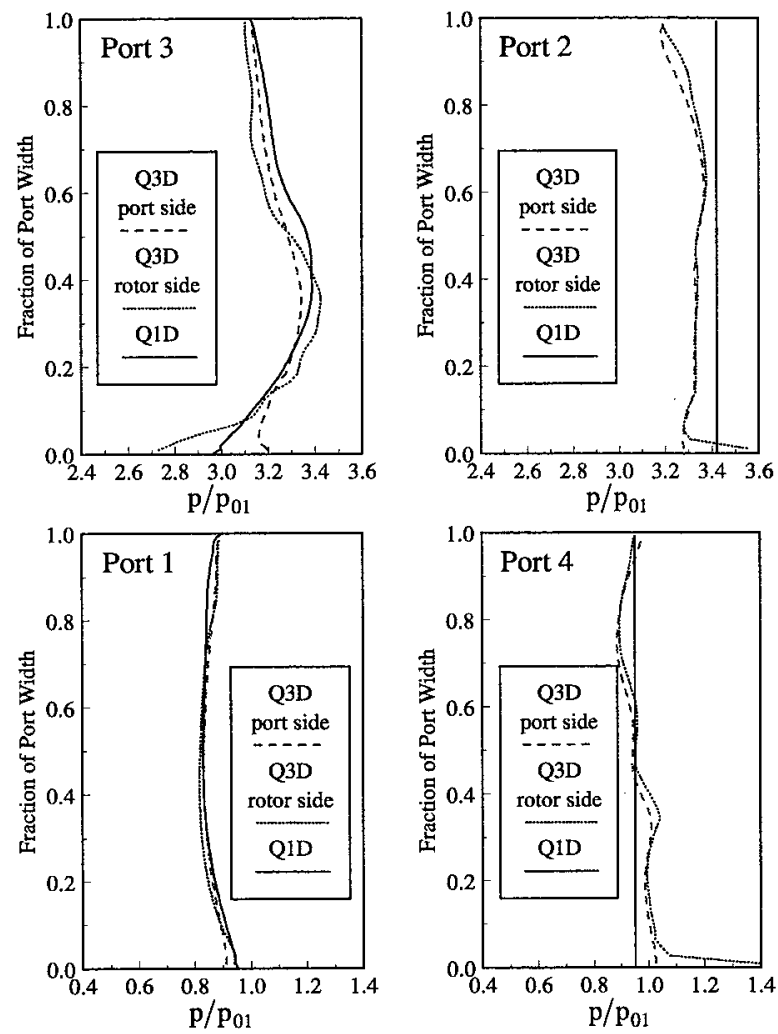

Figure 9 Port static pressure distributions, at the design point; on either side of the duct/rotor interface for Q3D, in the image cell for Q1D.

ratio, $\mathrm{T}_{04} / \mathrm{T}_{01}$, and ratio of flow through the combustor to flow through the inlet as that of Fig. 5. The contours have been shaded such that dark lines correspond to low temperature and light lines to high temperature. An additional weak shock wave can be seen running from the opening of port 1 to just after the closing of port 4 and reflecting back to the left end of the rotor. It can also be seen that the shock initiated at the opening of port 3 arrives at the right end of the rotor too early and reflects from the wall rather than from the leading edge of port 2. The reflected shock running from just below the port 2 opening to the port 3 closing is also mistimed, arriving late rather than coinciding with the stopping expansion wave which is initiated at the port 3 closing.

Despite the improper wave timing, Fig. 8 closely resembles Fig. 5 and suggests that the Q1D and Q3D codes obtain nearly the same solution to the wave rotor flowfield near design operating conditions. This is further evidenced in Fig. 9 which shows the computed static pressure distributions across each of the ports, at the rotor face, for the design operating point. For outflow ports 2 and 4 this distribution was specified as constant in the Q1D code(as long as outflow was
Table 3 Performance Prediction Comparison

\begin{tabular}{lccc}
\hline \hline \multicolumn{1}{c}{ Code (case) } & $\mathrm{p}_{04} / \mathrm{p}_{01}$ & $\mathrm{~T}_{04} / \mathrm{T}_{01}$ & $\dot{\mathrm{m}}_{2} / \dot{\mathrm{m}}_{1}$ \\
Q1D (near design) & 1.30 & 2.21 & 1.51 \\
Q3D (near design) & 1.28 & 2.20 & 1.60 \\
Q1D (idle) & 1.12 & 1.60 & 1.04 \\
Q3D (idle) & 1.13 & 1.67 & 1.10 \\
\hline \hline
\end{tabular}

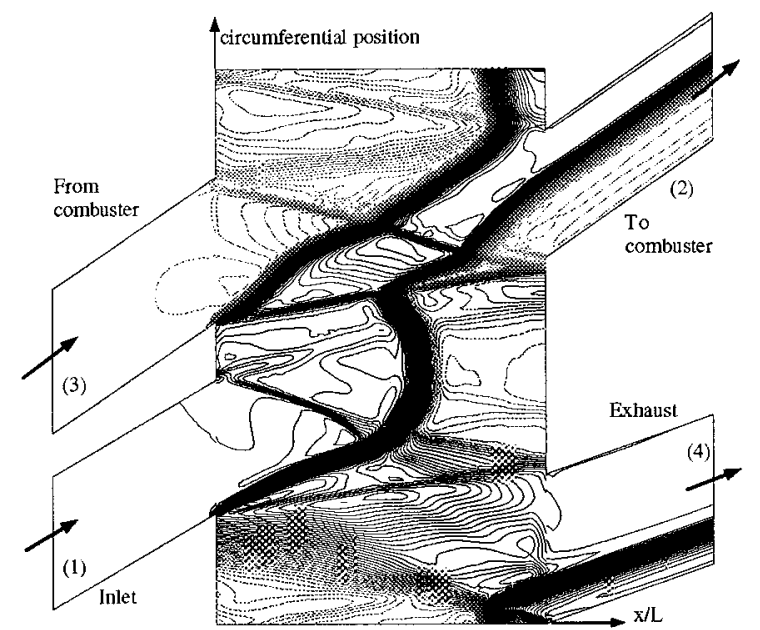

Figure 10 Q3D simulation of idle point wave diagram, with optimal passage height profile, neglecting gradual opening time, heat transfer, and leakage effects; shown using contours of temperature.

predicted). For the $\mathrm{Q} 3 \mathrm{D}$ code, the static pressure was specified at the ends of the ports 2 and 4 and the pressure at the rotor face was computed as part of the solution. The static pressures at the ends of the ports in the Q3D calculations were the same values as those assumed at the rotor face for the Q1D results. Figure 9 shows Q3D results just to the left and right of the rotor duct interface, and Q1D results in the image cell which may be thought of as being infinitesimally within the rotor. For the inflow ports 1 and 3 , the Q3D code again computed the rotor face static pressure distributions as part of the flowfield solution, with the boundary conditions being supplied by specified stagnation conditions at the entrances to the ports. For the Q1D results, the port flows are modeled and the rotor face pressure distribution is essentially a boundary condition ${ }^{9}$. Again, it is evident from Fig. 9 that the two codes predict nearly the same flowfield for this operating point.

\section{Idle Point}

Figure 10 shows the wave diagram representative of an idle condition of the wave rotor in an engine topping environment. The idle point corresponds approximately 

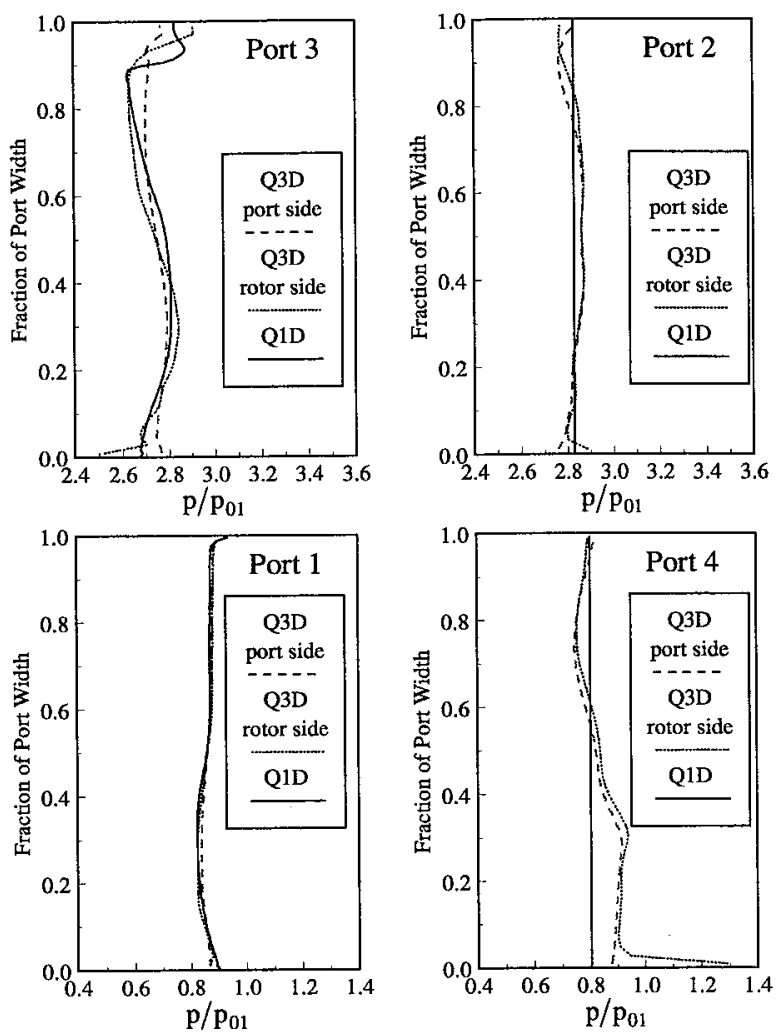

Figure 11 Port static pressure distributions, at the idle point; on either side of the duct/rotor interface for Q3D, in the image cell for Q1D.

to the bottom of the in-engine operating line of Fig. 7. The corrected rotor speed at this point is $86 \%$ of the design value. The overall temperature ratio, pressure ratio, and ratio of combustor to inlet mass flows are listed in Table 3. This table shows computed results from both the Q1D and Q3D codes for comparison. Like Fig. 8, it is clear from Fig. 10 that there are mistimed and spurious waves indicative of off-design operation; however, given the operating point, it is surprising that the timing is as good as it is. The most pronounced feature of the idle wave diagram is the gas path. It can be seen that a rather large fraction of the fresh air which enters port 1 never reaches the combustor, but is instead simply compressed, expanded, and sent out through port 4 . This leads to the large temperature gradients visible in the port 4 flow. The impact of such gradients on the performance of downstream turbine components is unclear, but it is worth noting that they are seen, although less severe, at operating points well above idle.

The port static pressure distributions at the rotor face, imposed, or computed by the Q1D, Q3D codes are shown in Fig. 11. Again it is clear that there is little

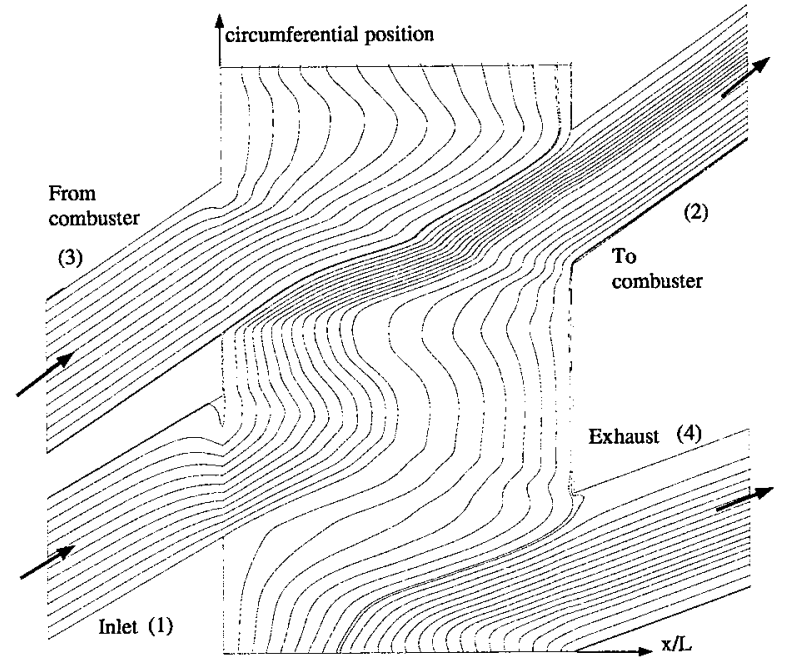

Figure 12 Streamlines from Q3D simulation of severe off design operation, with optimal passage height profile, neglecting gradual opening time, heat transfer, and leakage effects.

difference between the two codes, even at this offdesign operating situation.

\section{Severe Off-Design Point}

Although off-design situations where port flow reversals occur are possible, it was found with both the Q1D and Q3D codes that these were only encountered in extreme operating conditions, very far from the normal operating line of Fig. 5. Nevertheless, it is worthwhile to present one such operating point simply to illustrate the phenomenon. Figure 12 shows the streamline pattern from the Q3D simulation of an operating point in which the rotor speed and heat addition rate were held to the idle value, but the port 4 back pressure was increased until the corrected mass flow rate was $72 \%$ of the design value. With reference to Fig. 5 it is clear that such an operating point is far from normal in-engine operation. Regions of flow reversal or nearly stagnated flow are visible in Fig. 12 at the tops of ports 1, 3, and 4. Although not a wave diagram per se, the wave pattern can be seen in fig. 12 and can be identified as mis-timed. In particular, it is seen that the flow reversals in both ports 1 and 3 result from the impingement of left running shock waves. It is interesting to note that the flow reversal regions were correctly predicted by the Q1D code, despite the lack of port/rotor interaction simulation capability. This may be seen in Fig. 13 which shows the axial velocity component in each of the ports at the rotor face, as computed by the Q1D and Q3D codes. 

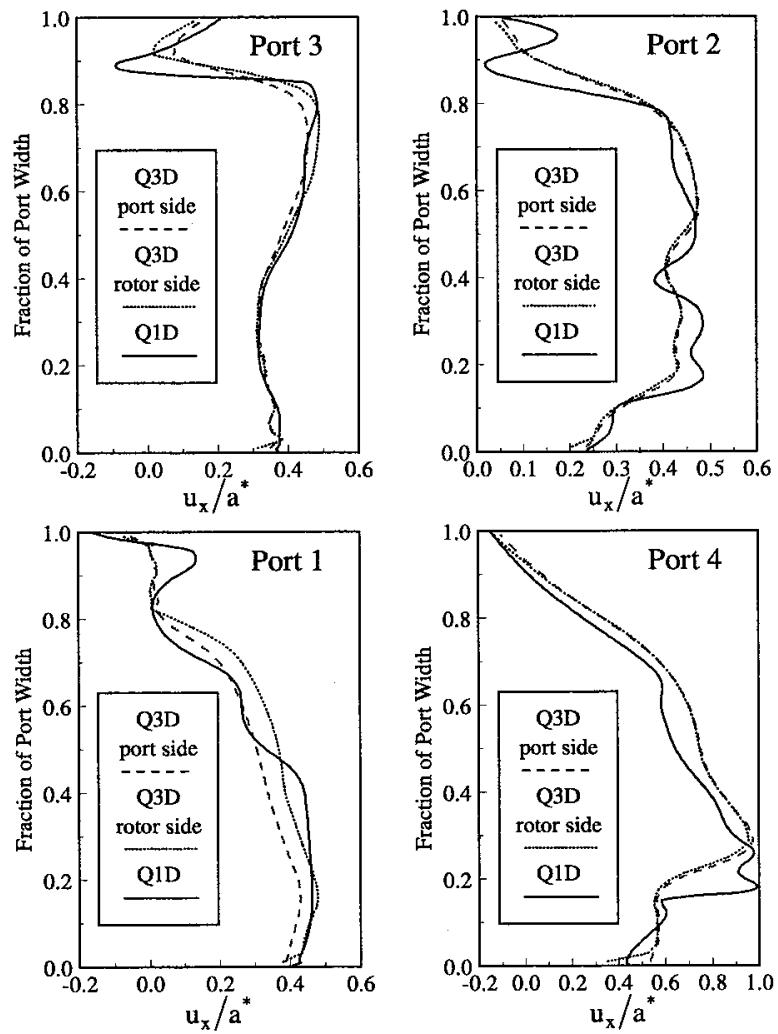

Figure 13 Port axial velocity distributions, at the severe off-design point; on either side of the duct/rotor interface for $\mathrm{Q3D}$, in the image cell for Q1D.

\section{Discussion}

The reasons that certain passage height profiles lead to enhanced performance are not clear. It is possible, of course, that the results are artificial, arising from the approximate nature of the quasi-one-dimensional assumptions; however, this does not seem likely since all of the height profiles examined had small values of $\mathrm{dh} / \mathrm{dx}$ (see Fig. 2). Nevertheless, the results should, at least, be validated with a higher fidelity numerical code.

In the absence of a complete explanation, it is worthwhile to at least make some pertinent observations about the wave processes. These observations concern the so called 'bottom half' of the four-port wave cycle. With reference to Fig. 5, this is the region which begins at the bottom of the $\mathrm{x}-\mathrm{t}$ space and extend to somewhere between ports 1 and 3 . In this region hot gas is expanded and sent out of port 4 while cold, fresh air is drawn in through port 1 and initially compressed by the coalescing shock wave which originates near the closing of port 4 and nearly terminates at the closing of port 1 . The overall pressure ratio of the wave rotor, $p_{04} / p_{01}$ is essentially determined by these two processes. The design objective is to maximize both the efficiency of

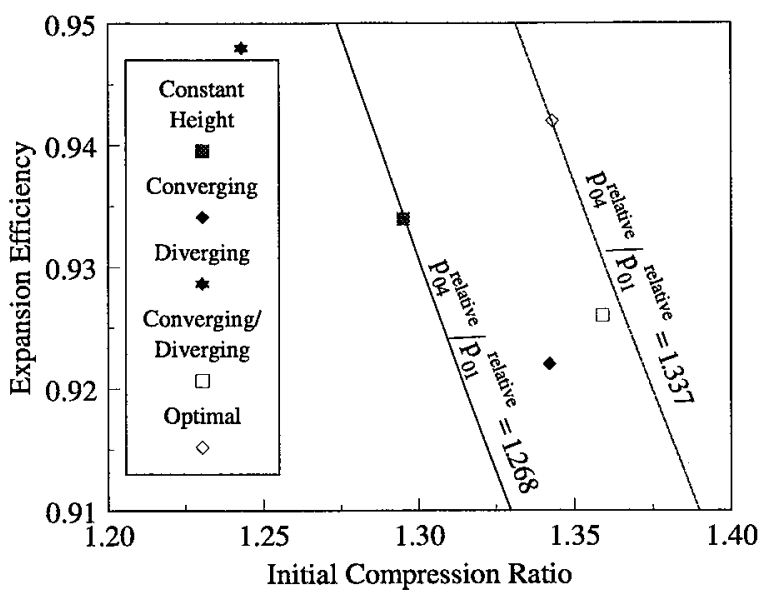

Figure 14 Plot of initial compression ratio, $\pi_{\text {ic }}$ versus expansion efficiency, $\eta_{e}$ for several height profiles.

the expansion process, and the initial compression of the fresh air. Since incidence, leakage, and heat transfer losses are neglected in the design algorithm, inefficiencies in the expansion and compression processes occur through viscous and gradual passage opening losses. Further inefficiencies in the expansion process are generated by assumed mixing of the nonuniform port 4 velocity profile. Figure 14 shows a plot of initial pressure ratio, $\pi_{\mathrm{ic}}$ versus the adiabatic expansion efficiency, $\eta_{\mathrm{e}}$ for several of the height profiles examined. The initial pressure ratio is defined as the ratio of mass averaged pressure in the passage after the closing of port 1 to the inlet stagnation pressure. The expansion efficiency is defined using the mixed stagnation conditions of port 4 and the conditions in the passage just before it opens to port 4 . Both $\pi_{\mathrm{ic}}$ and $\eta_{\mathrm{e}}$ are calculated in the relative frame of reference, where the design code operates. It was found that all of these points could be well described by the following function

$$
\frac{\mathrm{p}_{04}^{\text {relative }}}{\mathrm{p}_{01}^{\text {relative }}}=1.312 \pi_{\mathrm{ic}} \eta_{\mathrm{c}}-0.325
$$

Equation 7 can be used to obtain constant $\mathrm{p}_{04}^{\text {relative }} / \mathrm{p}_{01}^{\text {relative }}$ lines, two of which are also shown in Fig. 14. Moving to the right of these lines implies higher performance. Examining Fig. 14, it is interesting to note the relative positions of the various profiles. Note, for instance that the diverging profile has improved expansion efficiency over the constant height profile, but the compression ratio is considerably lower. Similarly, the optimal converging profile has lower efficiency but higher compression ratio resulting in an 
overall improvement in $\mathrm{p}_{04}^{\text {relative }} / \mathrm{p}_{01}^{\text {relative }}$ from the baseline constant height profile. The optimal converging-diverging profile showed improvement over the converging profile largely through increased initial compression ratio. The optimal converging-divergingconverging profile showed only slight improvement over the converging-diverging profile; however, this was achieved through a reduction in initial compression and a large increase in expansion efficiency.

It is interesting to note as an aside that the vertex of converging diverging profiles, and the first vertex of the converging-diverging-converging profiles occurred very close to the intersection, in the Fig. $5 \mathrm{x}-\mathrm{t}$ space, of the port 4 to port 1 coalescing shock and the hot/cold interface running leftward from the opening of port 1.

Clearly, the above discussion does not satisfactorily explain the improved performance observed for certain passage height profiles. It is hoped however, that it will at least provide a helpful starting point from which future studies may benefit. It is certainly clear that more work is needed and warranted in this area.

\section{Concluding Remarks}

Variable passage height has been numerically examined in this paper as a means toward improving performance in four-port, through-flow wave rotors. Although the physical mechanisms are not yet clear, the results indicate that substantial improvements can be obtained with certain profiles. In particular, an overall pressure ratio increase from 1.203 for the constant passage height baseline to 1.255 for a height profile described primarily by three slopes and two vertices was obtained. This substantial improvement suggests that a systematic optimization procedure, grounded in an understanding of the mechanisms behind the improvements is warranted and may lead to even more impressive results.

The off-design simulation results clearly demonstrated the robust operational capabilities of 4-port, throughflow wave rotors in general, and parenthetically, demonstrated the capabilities of and compatibility between the Q1D and Q3D computational approaches to the flowfield solution.

\section{Acknowledgements}

The authors wish to sincerely thank Dr. Jack Wilson of NYMA Inc. for providing the Method of Characteristics results presented in Fig. 4. The authors also gratefully acknowledge the work of Dr. Chris Miller of the NASA Lewis Research Center for providing the twodimensional simulation results presented in Fig. 4.

\section{References}

1. Welch, G. E., Jones, S. M., Paxson, D. E., "WaveRotor-Enhanced Gas Turbine Engines," ASME Journal of Engineering for Gas Turbines and Power, Vol. 119, No. 2, 1997, pp. 469-477; also NASA TM-106998, July, 1995.

2. Jones, S. M., Welch, G. E., "Performance Benefits for Wave Rotor-Topped Gas Turbine Engines," ASME 96-GT-075, June, 1996; also NASA TM 107193, June, 1996.

3. Wilson, J., Paxson, D. E., "Wave Rotor Optimization for Gas Turbine Engine Topping Cycles," Journal of Propulsion and Power, Vol. 12, No. 4, 1996, pp. 778-785; also NASA TM106951, May, 1995.

4. Paxson, D. E., "A Numerical Model for Dynamic Wave Rotor Analysis," Journal of Propulsion and Power, Vol. 12, No. 5, 1996, pp. 949-957; also NASA TM-106997, July, 1995.

5. Snyder, P. H., Fish, R. E., "Assessment of a Wave Rotor Topped Demonstrator Gas Turbine Engine Concept," ASME 96-GT-041, June, 1996.

6. Klapproth, J. F., "Wave Engine Project," General Electric Quarterly Report, R60FPD284, 1960.

7. Wilson, Jack, "The Effect of Area Variation on Wave Rotor Elements," NASA Contractor Report, to be published.

8. Paxson, D. E., "A Comparison Between Numerically Modeled and Experimentally Determined Wave-Rotor Loss Mechanisms," Journal of Propulsion and Power, Vol. 11, No. 5, 1995, pp. 908-914; also NASA TM-106279, June, 1993.

9. Paxson, D. E., "Recent Improvements to and Validation of the One-Dimensional NASA Wave Rotor Model," NASA TM-106913, May, 1995.

10. Anderson, D. A., Tannehill, J. C. , Pletcher, R. H., Computational Fluid Mechanics and Heat Transfer, McGraw-Hill, 1984.

11. Roe, P. L. "Characteristic Based Schemes for the Euler Equations," Annual Review of Fluid Mechanics, 1986, Vol. 18, pp. 337-65.

12. Rudinger, G., Wave Diagrams for Nonsteady Flow, D. Van Nostrand Company, New York, 1955.

13. Hall, E. J., Topp, D. A., Delaney, R. A., "ADPAC User's Manual," NASA CR 195472, April , 1996.

14. Benade, Arthur H., Horns, Strings, and Harmony, Anchor Books, 1960.

15. Lear, W. E., Candler, G. V., "Direct Boundary Value Solutions for Wave Rotor Flow Fields," AIAA 93-0483, January, 1993.

16. Lindau, J. W., Multidimensional Dynamic Compression System Modeling, $\mathrm{PhD}$. Dissertation, Virginia Polytechnic Institute, Blacksburg, Virginia, 1995. 
17. Welch, G. E., "Macroscopic Balance Model for Wave Rotors," AIAA 96-0243, January, 1996, also NASA TM 107114.

18. Hirsch, C., Numerical Computation of Internal and External Flows, vol. 2, John Wiley \& Sons, New York, 1990.

\section{Appendix I Q3D Description}

The Q3D code is similar in physical basis to the model presented by Lear and Candler. ${ }^{15}$ Finite rotor passage widths are neglected, and the limiting condition is then steady in the stationary reference frame. With this assumption made, flow may be obtained as a steadystate boundary value problem. This problem was cast using inviscid flow equations and integrated by numerical techniques.

Several differences between the code used here and that presented by Lear and Candler exist. First, in the present code, the effects of passage height profile variation, aerodynamic incidence, and viscosity were modeled. Second, the upwind fluxes in the present code used Roe flux difference splitting instead of the StegerWarming technique. ${ }^{11}$ Third, second order spatial accuracy was obtained using van Albada limited MUSCL differencing. ${ }^{18}$

Other flux limiters were also considered. The Superbee limiter was noted in the literature for its ability to resolve contact discontinuities. ${ }^{18}$ In testing with the Q3D code, resolution of contact surfaces appeared better with the Superbee limiter than with the van Albada limiter. However, the Superbee limiter yielded solutions containing nonphysical oscillations and appeared to inhibit steady state convergence. Overall, cycle performance predictions were only slightly affected by the choice of limiter.

For cases considered here, within each port, there was no profile height, or mean radius variation, therefore, the modeled flow was strictly two-dimensional. Thus, this flow was modeled with the two-dimensional, inviscid, Euler equations. Each port and the rotor was numerically integrated on a separate structured grid zone. Communication across inter-zone interfaces was first order accurate. Boundary conditions were applied in a first order manner except for the periodic boundary which was second order accurate and consistent with the interior fluxes.

Within the rotor, the theoretical limit of infinite passage solidity was applied. Therefore, in the frame of reference moving with the rotor, the flow was always aligned with the rotor passage. As flow crossed the interface between the port and the rotor, in the frame of reference of the rotor, it was assumed that no work was done. In addition to no work in the rotating frame of reference, the assumption was made that some loss due to aerodynamic incidence could be applied at the interface between the port and the rotor. The quantitative form of this loss was applied as a discontinuous decrease in relative total pressure for flow boarding the rotor across the interface. The loss models applied here were applied in a similar manner to that described by Paxson. ${ }^{9}$ It was also necessary to specify the circumferential velocity on the port side of the rotor to port interface. For results presented here, the circumferential velocity was allowed to convect with the axial flow. Thus there was no aerodynamic deviation for flow leaving the rotor. Coupled with mass continuity, this completed conservation conditions across the rotor port interface. 

Public reporting burden for this collection of information is estimated to average 1 hour per response, including the time for reviewing instructions, searching existing data sources, gathering and maintaining the data needed, and completing and reviewing the collection of information. Send comments regarding this burden estimate or any other aspect of this collection of information, including suggestions for reducing this burden, to Washington Headquarters Services, Directorate for Information Operations and Reports, 1215 Jeffers Davis Highway, Suite 1204, Arlington, VA 22202-4302, and to the Office of Management and Budget, Paperwork Reduction Project (0704-0188), Washington, DC 20503.

\begin{tabular}{|l|l|l|}
\hline 1. AGENCY USE ONLY (Leave blank) & $\begin{array}{r}\text { 2. REPORT DATE } \\
\text { June } 1997\end{array}$ & $\begin{array}{r}\text { 3. REPORT TYPE AND DATES COVERED } \\
\text { Technical Memorandum }\end{array}$ \\
\hline
\end{tabular}

4. TITLE AND SUBTITLE

Numerical Assessment of Four-Port Through-Flow Wave Rotor Cycles

With Passage Height Variation

6. AUTHOR(S)

D.E. Paxson and Jules W. Lindau

7. PERFORMING ORGANIZATION NAME(S) AND ADDRESS(ES)

National Aeronautics and Space Administration

Lewis Research Center

Cleveland, Ohio 44135-3191

9. SPONSORING/MONITORING AGENCY NAME(S) AND ADDRESS(ES)

National Aeronautics and Space Administration

Washington, DC 20546-0001
5. FUNDING NUMBERS

WU-505-26-33

8. PERFORMING ORGANIZATION REPORT NUMBER

E-10787

10. SPONSORINGMONITORING AGENCY REPORT NUMBER

NASA TM-107490

AIAA-97-3142

\section{SUPPLEMENTARY NOTES}

Prepared for the 33rd Joint Propulsion Conference and Exhibit cosponsored by AIAA, ASME, SAE, and ASEE., Seattle, Washington, July 6-9, 1997. D.E. Paxson, NASA Lewis Research Center and Jules W. Lindau, National Research Council-NASA Research Associate at Lewis Research Center. Responsible person, D.E. Paxson, organization code 5530, (216) 433-8334.

12a. DISTRIBUTION/AVAILABILITY STATEMENT 12b. DISTRIBUTION CODE

Unclassified - Unlimited

Subject Category 07

This publication is available from the NASA Center for AeroSpace Information, (301) 621-0390.

13. ABSTRACT (Maximum 200 words)

The potential for improved performance of wave rotor cycles through the use of passage height variation is examined. A Quasi-one-dimensional CFD code with experimentally validated loss models is used to determine the flowfield in the wave rotor passages. Results indicate that a carefully chosen passage height profile can produce substantial performance gains. Numerical performance data are presented for a specific profile, in a four-port, through-flow cycle design which yielded a computed $4.6 \%$ increase in design point pressure ratio over a comparably sized rotor with constant passage height. In a small gas turbine topping cycle application, this increased pressure ratio would reduce specific fuel consumption to $22 \%$ below the un-topped engine; a significant improvement over the already impressive $18 \%$ reductions predicted for the constant passage height rotor. The simulation code is briefly described. The method used to obtain rotor passage height profiles with enhanced performance is presented. Design and off-design results are shown using two different computational techniques. The paper concludes with some recommendations for further work.

\section{SUBJECT TERMS}

Wave rotor; Numerical simulation; Computational fluid dynamics

15. NUMBER OF PAGES

$\mathrm{A} 03$

17. SECURITY CLASSIFICATION
OF REPORT
Unclassified

18. SECURITY CLASSIFICATION
OF THIS PAGE
Unclassified
19. SECURITY CLASSIFICATION OF ABSTRACT

20. LIMITATION OF ABSTRACT 